dogmatic, but merely offer this as a possible assisting factor in some cases.

In towering from the second kind of injury, the bird can and sometimes does fly away from the place where it fell, and, after retrieving, concordant testimony shows lesion in the neighbourhood of the eyes, whence blindness has been assumed to be the cause. The fact that this very rarely occurs, perfectly agrees with the objection that the smallness of the head is adverse to the theory of cerebral injury being the invariable cause. It has further been noticed that these birds seldom move until they are touched. Whether, attention having been drawn to this subject, future observers will detect a difference in the towering of birds that may, and those that cannot, rise again, is hard to say, but I hope, in the interests of science, all pertinent observations will be communicated and admitted into the columns of NATURE.

Faringdon, Berks, December II J. Hopkins WALTERS

The Tasmanians

I SEE it stated in NATURE, vol. xiv. p. 242 (which has just reached us), that $\mathrm{M}$. Castelnau, French Consul at Sydney, states in a letter " to the Geographical Society of Paris, read at its last sitting, that the only four Tasmanians living were presented at the last levée held by the Governor of Tasmania."

I cannot imagine how $M$. Castelnau can have allowed himself to propagate such an error. It is quite true that four Tasmanian aborigines were presented at a governor's levée, but the presentation occurred just ten years ago, and all the four have long since been gathered to their fathers.

In reference to the last paragraph in your note, I regret to say that we really "have seen the last of them." The sole survivor of this singular race, a female, by name Trucanini, died a few months ago at the age of seventy or thereabouts. The "penultimate" aborigine was King Billy, who preceded Trucanini to the grave three years ago.

Hobart Town, October $2 \mathrm{I}$

\section{Algoid Swarm-spores}

IN a note on algoid swarm spores, published in NATURE, vol. xv. p. 15 , reference is made to the new investigations of M. Sachy, who considers the motion and accumulation of spore as due to currents produced by differences of temperature in the water, and not at all to the action of the light causing the living swarm-spores to move. I do not know the experiments by which this result has been reached; but the following seems to me a confirmation of the new theory.

At a distance of about 5 feet from the window of my room is placed a cylindrical glass vessel of $\mathbf{I}$ foot in diameter, and containing only some sphagna and microscopical crustacea. This aquarium has been kept unshaken for four years.

Now a great quantity of green alga is collected on the side opposite to the window, while the side turned towards the light is covered with a considerable number of little particles of an amorphous matter, arranged in pretty regular cloudy forms, containing nothing but débris of plants or animals, and a few desmidia.

These particles, which cannot be considered as living matter, arise from the light mud which covers the sand at the bottom of the aquarium. The right and left sides of the vessel remain quite clean.

I should much like to know if any of your readers have observed similar facts.

29, rue Saubat, Bordeaux, December 17

\section{Meteor}

I SAW the meteor spoken of by your correspondent (ante, p. $(70)$ at Blackwater on Wednesday the $13^{\text {th }}$ inst. at 4.45 P. M. as I was passing down St. James's Square. It was apparently of somewhat greater magnitude than the planet Jupiter, and passed from north to south, till it disappeared behind the houses.

Your correspondent will find two notices of the same meteor in the Times of the 15 th inst.

P. L. Sclater

\section{ON THE RELATION BETWEEN FLOWERS AND INSECTS 1}

$T \mathrm{HE}$ habit possessed by our honey-bee of feeding itself from flowers, and its corresponding faculty of deciding amongst different species and divining the situa-

${ }^{2}$ Abstract of an article in the Bienen Żitung by Dr. H. Müller. tion of the honey, is, in the first instance, derived from the common parents of all the Hymenoptera. It probably even comes from such remote ancestors as the leaf-cutting wasp, from them passes to the gall-flies, the ichneumons, and the hunting-wasps, from which latter it goes to the allied species of ants and bees. We may see all these families of Hymenoptera fecing on the honey and pollen of flowers, and manifesting a certain, if not always very obvious, intelligence in choosing the flower to be visited.

The various families of wasps differ amongst each other as to their ingenuity in finding the honey, but it is in the bees that we first arrive at the more complex use of the food, i.e., not merely for the insect itself, but also for its young, combined with such intelligence in its discovery, as proves that the most highly developed form of insect is the one which profits by the honey lying most concealed. The following observations may throw some light on the foregoing statements :--

I come to the conclusion that the Hymenoptera enumerated have a certain degree of intelligence, at least with regard to honey that is in sight, from never having seen leaf-cutting wasps or ichneumons, and still less hunting-wasps or bees, seek honey so long in flowers where it does not exist as is the case with some species of beetles, which feed frequently or exclusively on the nourishment derived from flowers.

However, even very highly-organised insects are at times misled, and Dr. Müller cites one case in which Melampyrum aryense was surrounded by a crowd of ichneumons, bees, \&c., seeking the honey in vain, the only one which succeeded in obtaining it being Bombus hortorum, which has the longest proboscis of all our humblebees.

It cannot be said either of the leaf-cutting wasps or of the gall-flies that they attain a high degree of intelligence in finding concealed honey, and to these we may add the ichneumons which are frequently found on plants with the honey easily seen (Umbelliferre, Listera, Ruta, \&c.), much more rarely on those where it is partially concealed (Cruciferre, Spiræa, Salix), and quite as an exception on those in which it is completely hidden (Gypsophila, Malva, Mentha.)

When once a family of Hymenoptera has attained to the point of intelligence of providing food for its young and placing it along with the eggs, we see it develop greater dexterity in its search for honey. In comparing, for instance, the statistics of the visits of the leaf-cutting wasp and the hunting-wasp, we find that even the most developed leaf-cutting wasp only attempts to rob those flowers whose simple forn renders the honey easy of access. Even those of Bryonia and Reseda seem unattainable by them. On the contrary, we see the huntingwasps attack not only these, but also flowers specially adapted to the movements of the fossorial Hymenoptera, for example, Echium, the Labiates, and the Papilionacex, and also the pendent bells of Symphoricarpus, which only allow ingress to the honey from below. It must be deduced from the above statements that flowers and the insects which visit them are adapted to each other, and have gone through corresponding degrees of development at each period of the world's history. For example, if my view of the origin of the Hymenoptera is correct, there has been a time when species with an ovipositor were the only Hymenoptera ; and when only regular, open, turnedup flowers of as low a form as Salix existed, while Reseda, Echium, the Labiates, the Papilionacea, \&c., \&c., have been developed at a later period after the species of Hymenoptera had developed to the point of preparing a place for their young.

We may therefore see how through the transition of hunting-wasps to the habits of bees, and further within the bee-like family, dexterity in acquiring the food has increased. The species perhaps most nearly allied to the ancestors of the bee-Prosopis-is, as to its organisation, 
on the same footing with the hunting-wasp, and, as to the length of its tongue, is even but little more highly developed. The assiduity with which it visits the flowers, its practice in seeking those where the honey is conccaled, its well-established habit of feeding its young entirely on food derived from flowers, all place it above the average of its ancestral species. Even, however, among these ancestral species-the hunting-wasps-are certain kinds whose love for flowers has far surpassed their power of rearing a family, and these, favoured by their large size and length of tongue, have attained still greater dexterity in getting at concealed honey than Prosopis.

Out of eighty-five visits to flowers by different species, there were of Prosopis :-

On flowers with the honey apparent, $19=22^{\circ} 4$ per cent.

On flowers with the honey somewhat concealed, but still fairly apparent, $19=22 \% 4$ per cent.

On flowers with the honey concealed, but easily reached through the formation of the mouth, $28=32^{\circ} 9$ per cent.

On flowers with the honey entirely concealed, which are specially adapted to the burrowing Hymenoptera, $8=9^{4}$ per cent.

On flowers without honey, or at least only having pollen as far as Prosopis is concerned, II $=12.9$ pex cent.

Some of the hunting-wasps appear to show even more intelligence than Prosopis in the search for honey, and this will appear still more forcibly if we leave out the flowers which only yield pollen, when the total result is for the wasps $35^{\circ} 3$ per cent., for the Prosopis 48.6 per cent.

The following table will show at a glance how far the hunting-wasps are above the leaf-cutting wasps, how fax the former are surpassed by Prosopis, and how far the hunting-wasps, most eager for flowers, again surpass the Prosopis.

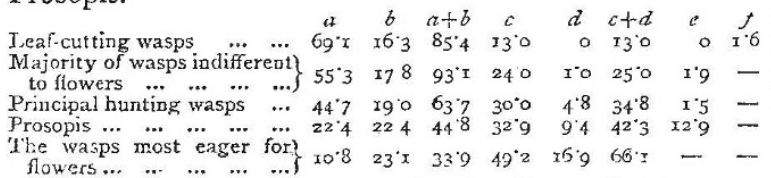

If we look down the perpendicular lines of this table from top to bottom we shall see the frequency of the visits to the flowers with the honey apparent $(a)$ even if we add the visits to the flowers with the partially seen honcy $(a+b)$ steadily decline, though the visits to the flowers with partially concealed honey $(b)$ steadily increase. In still more rapid ratio the frequency of the visits to the honey entirely concealed, increases $(c+d)$, both in the case of those flowers whose honey is easily attainable through the simple form of the corolla (c), and those specially adapted to the burrowing Hymenoptera $(d)$.

With regard to the flowers yielding only pollen $(e)$, the Prosopis shows a remarkable advance on the other Hymenoptera, probably caused by the great need the young fed from flowers have of the pollen.

The results of a careful series of observations, prolonged over a course of five summers, brings us to the following conclusions :-

I. The Tenthredos stand, as regards the rearing of their young and in their general intelligence, as well as in their capacity of finding and acquiring concealed honey, the lowest of all the Hymenoptera we have considered. They visit flowers with the honey altogether apparent much more frequently than those with the honey wholly or partially concealed, and the latier only in the case of those with a low and simple organisation.

2. The hunting-wasps, which, as has been previously shown, stand decidedly above the Tenthredos, show also a decidedly higher power of finding honey. Even when the most intelligent and flower-loving families are excluded, a high percentage among the hunting-wasps is found visiting flowers with concealed honey, and a lower visiting flowers where the honey is apparent; they even seek some flowers whose formation shows them to be adapted to the fossorial Hymenoptera. All this progress appears still more remankable when we compare the whole group of Tenthredos with the whole group of hunting-wasps.

3. Prosopis, the least highly-developed bee, and one which does not stand higher than the hunting-wasp:, cither in general capacity or in care for its young, is yet compelled, through the greater requirements of the latter and their need of pollen, to visit both flowers with concealed honey and flowers which only produce pollen.

4. Certain species of hunting-wasps stand above the Prosopis, both in size and in the length of the proboscis; these, however, only seek food from flowers for themselves, and not for their young.

We may now hope through the following steps to obtain some idea how the honey-bee has acquired its peculiar capacity for finding concealed honey.

All our European bees, except Prosopis and the parasitic species, have their hairy covering specially adapted to collect pollen. This apparatus forms a characteristic by which they are divided into two families, namely, those which collect the pollen with a brush on the lower side of the body, and those which' collect it with the pencil-like hairs of the hind legs.

In the former family there are various degrees of development in the pollen-collecting apparatus, difficult alike to describe or distinguish; and as the relationship of these species to the honey-bee is but remote, we may content ourselves with glancing at this group as a whole.

The second group, on the contrary, offers a steady series of degrees of development which we may now compare with each other and with Prosopis.

Passing over the first step-sphecodes, we come to Andrena and Halictus, whose size and length of proboscis places them distinctly above Prosopis. Their visits to flowers rise from 7.4 per cent. in the case of flowers with the honey altogether apparent, to $51^{\circ} 6$ per cent. to the flowers of complex form and with the honey entirely concealed.

The genera Eucera, Anthophora, and Sarapoda reach the highest point of intelligence as regards flowers of all cur native bees, the length of their proboscis varying from ten $1021 \mathrm{~mm}$., one of the humble-bees (Bombus horform being the only one that can in this respect compare with them.

The three above-mentioned genera, out of fifty-six visits to flowers, paid none to those with the honey apparent, but $9 \mathrm{I} \cdot \mathrm{I}$ per cent. to those with either concealed honey of complex form, or with both characteristics united.

There is no further example of increased development of the proboscis in this family, but they have attained a further step in the transformation of the thigh brushes into pollen-baskets, and above all in the establishing the community of life and of labour which distinguishes the humble hive bees. From observations made on the latter, however, it appears that increased development shows a certain return to the flowers containing more visible honey, the honey bee, out of 520 visits observed, going to such flowers at the rate of 0.8 per cent., the hive-bee, I94 visits being observed, at the rate of 3.1 per cent.

The following table is fuller than the previous one :-

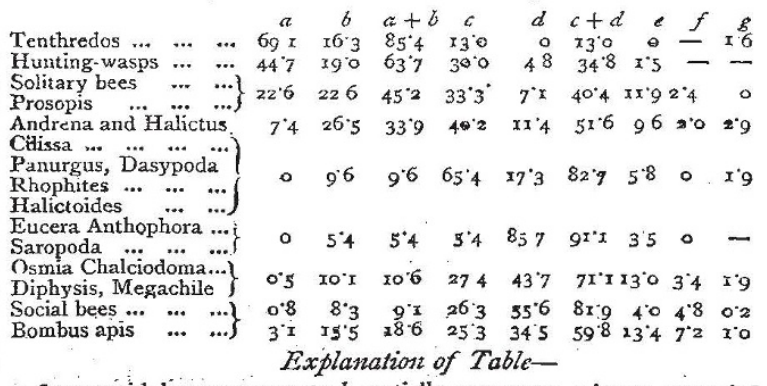

$a$, flowers with honey apparent; $b$, partially apparent; $c$, honoy concealed but easily reached; $d$, concealed but adapted to a short proboscis; $e$, fowers only possessing pollen; $f$. useless attempts to get honey by making a hoke, as on Dirlytra; $g$, flowors without honey. 
The visits to the flowers with partially apparent honey $a+b$ steadily diminishes from the Tenthredos to Andrena and Halictus, but so that the diminution of the visits entirely refers to the flowers with the honey apparent, while, on the contrary, the flowers with honey partially hidden are visited with still greater frequency.

In the case of some solitary bees, the disinclination to flowers with the honey apparent has reached to their total abandonment.

The transition to social life brings the development in the second group, of which we have been treating, to an end, as, in proportion as the number of individuals in a community increases, the necessity for food forces them to seek honey where they can, and it is indeed touching to see the unwearied diligence with which the hive-bee will collect almost imperceptible drops of honey from even the smallest flowers.

The perfection which the family of bees, viewed as a whole, has attained, beginning with Prosopis, and rising to the most perfect of the solitary bees belonging to the group which collect pollen on their hind legs, consist :-

x. In the increasing development of the pollen-bearing apparatus.

2. In the prolongation of the lower part of the mouth.

3. In the increasing size of the individuals.

'The first is seen best in the humble and hive-bees ; the third is very marked in the humble-bee, while the length of the proboscis reaches its furthest point in Anthophora. The hive-bee has a more perfect pollen apparatus than the humble-bee, but is inferior to the latter in size and length of proboscis, and only succeeds in obtaining more honey through its more populous communities.

It is well known that as a rule every hive-bee occupied in seeking food from flowers specially devotes itself to a particular species, passing by others, however rich in pollen or honey. The advantages of this arrangement are obvious, much fewer visits being made in vain to flowers already plundered, and much greater dexterity being attained in the case of flowers with complex forms.

'Two questions remain to be decided-

r. Does each individual bee collect pollen and honey from a single plant only (to which it has become adapted by instinct, i.e., by inherited custom)?

2. Does the hive-bee possess a greater degree of intelligence in deciding among the different species of plants than the humble-bee and other lower forms?

The first question must be met with a decided negative; the second, as far as observation has yet gone, cannot be answered with certainty. It would scarcely be of advantage to the bee-community, whose object is the exploitation of as many flowers as possible, if its instincts as to special tribes were hereditary.

It is, on the contrary, to be observed in the hive-bee that each bee makes various essays before deciding on any special tribe of flowers. For example, we have seen a hive-bee in vain attempt to obtain the honey of Iris tseudacorus, and then fly to Ranunculus acris, which it sucked at for some time. Another more than once bored through the spur of Orchis latifolia, loading its head with two little clubs of pollen, and then flying to the flowers of Lychnis floscuculi.

A third, wandering over a field full of weeds, visited one after another Veronica hederafolia, Lithospermum arvense, Sisymbrium thalictrum, and Viola tricolor.

These and similar facts show that there can be no question of inherited preferences for certain plants in individual bees, and that the fact of each bee being devoted to certain plants is only to be ascribed to the subordination of the interests of the individual to that of the state. The humble-bee approaches the hive-bee in the peculiarity of keeping to certain species, as well as in the number and keeping of its community. However, though chiefly confining itself to the plants accessible to it alone, as for example, Lamium album, \&c., there are fairly numerous cases in which the humble-bee goes to other plants, and its baskets are often found full of very varied kinds of pollen.

Even in solitary bees, the special preference for special kinds of flowers is a frequent habit. For example, $A n$ drena hattorfiana is found on Scabiosa arvensis, Cilissa melamura on Lythrum salicaria, \&c.; but this preference evinced by some solitary bees for a single species of flower sufficing all their needs is radically different from the practised and exhaustive pillage of all flowers by a bee community, in which special individuals are told off to gain the produce, however small, of special families of plants. At first I believed I could answer the other question propounded above, i.e., whether the hivebee promises a higher degree of intelligence in distinguishing different genera of plants than the hummingbee and other lower forms, in the affirmative, on the ground of the following observations :- In a field grown over with weeds I saw one of our more intelligent humblebees, Bombus agrorm, visit without distinction the little whitish flowers of Viola tricolor var. arvensis, and those of Lithospermum arvense, the same size and colour, but evidently differing in form, while avoiding all other plants. I had, indeed, seen the hive-bee mistake the flowers of Ranunculus arvensis for those of $R$. bulbosus, those of Trifolium repens for those of Trifolium fragifernm many times, but had then never seen it make so great a mistake as that I have recorded of the humble-bee. From this I concluded that the hive-bee is more practised in distinguishing various species than the humble-bee. As, however, I later saw the hive-bee go from the blue violet to a hyacinth of the same colour, and back again, I felt convinced that the grounds of my conclusion were somewhat defective, and I can only leave the decision of this question to further observations. As far as my own experience is concerned, I am inclined to believe that the hive-bee, as well as all other bees which we see preferring special families of plants, are much more led by colour and size than by any clear apprehension of the form of the flowers.

A. J. G. D.

\section{AN ACCOUNT OF DUPLEX TELEGRAPHY}

THE introduction of the duplex system of working not only upon land-lines, but on sub-marine cables, is without doubt the most important advance recently made in electric telegraphy.

Duplex telegraphy may be defined as the art of telegraphing in opposite directions simultaneously along one line wire.

It is claimed by M. Zantedeschi in papers read before the Academy of Sciences, Paris, in 1855 , that as early as I829 he had suggested and demonstrated the possibility of working "duplex;" but until the year 1853 there do not appear to have been any noteworthy attempts made to effect it practically. In that year, Dr, Gintl, a director of Austrian telegraphs, described a system of duplex telegraphy to the Academy of Sciences, Vienna, and practically tested it on the land-lines between Vienna and Prague.

'The principle underlying this and all other systems, is that the outgoing currents at a station shall not sensibly affect the receiving instrument there, while, at the same time, the latter is free to be affected by the incoming currents, so to speak, from the other station. That is to say, no signals are made at a station by its own sending currents, unless when these are interfered with by the sending currents of the other station.

Gintl's plan was as shown in Fig. $x$. The receiving instrument, RI, was wound by two separate wires, one long and thin, the other short and thick. The long wire, shown by a full line, was connected at one end to the line $\mathrm{L}$, and the short wire, shown by a dotted line, was connected at one end to a local, or, as it was called, a "com- 